\title{
Non-Animal Models in Experimental Subarachnoid Hemorrhage Research: Potentials and the Dilemma of the Translation from Bench to Bedside
}

\author{
Cihat Karadag ${ }^{1} \mathbb{D}$. Jay Gopalakrishnan ${ }^{2}$. Christiane von Saß ${ }^{1,3} \cdot$ Jan F. Cornelius $^{1}$ • Daniel Hänggi ${ }^{1}$. \\ Jasper Hans van Lieshout ${ }^{1} \cdot$ Marcel A. Kamp ${ }^{1,3}$
}

Received: 24 September 2021 / Revised: 24 September 2021 / Accepted: 27 September 2021 / Published online: 29 October 2021

(c) The Author(s) 2021

\section{Dear Editor,}

Worldwide, strokes are considered the second most prevalent cause of death. Around 7\% are caused by subarachnoid hemorrhage (SAH), which in turn is associated with startlingly high morbidity and case fatality rate (CFR) of about $50 \%$ [1-3]. Translational approaches in the last decades have aimed to identify and establish new therapeutic approaches. Despite over 750 animal research studies having been published - some of which yielded promising results - translation from bench to bedside has largely failed so far $[4,5]$. Potential reasons have previously been discussed extensively and include differences in brain and vessel anatomy, (patho-) physiology, genetics, and pharmaco-dynamics depending on the species and the drugs used [6-8]. Consensus definitions of important end points, such as delayed cerebral ischemia (DCI), are not generally used [9, 10]. Experimental SAH and SAH following aneurysm rupture in human beings often cannot be compared directly due to different pathophysiology and outcome parameters, e.g., vastly differing CFR [11]. Consequently, the use of animal models has been criticized for both scientific and ethical reasons.

Looking for a solution for this predicament, the suitability of (potential) non-animal experimental alternatives to study the complex pathophysiology after SAH has to be evaluated.

Cihat Karadag

Cihat.karadag@hhu.de

1 Department of Neurosurgery, Medical Faculty, HeinrichHeine-University, Moorenstr. 5, 40225 Duesseldorf, Germany

2 Institute of Human Genetics, Medical Faculty, Heinrich-Heine-University, Duesseldorf, Germany

3 Department of Neurosurgery, Jena University Hospital, Friedrich-Schiller-University Jena, Am Klinikum 1, 07747 Jena, Germany
However, so far, only a few preclinical in vitro models have been described for experimental SAH:

1. The most common preclinical SAH non-animal models are cell culture models. By growing individual cell populations, specific (cellular) pathomechanisms can be closely monitored, such as neuroinflammation, neuronal injury following $\mathrm{SAH}$, and toxic side effects of blood and its components. However, when interpreting the results, the simplification of complex in vivo conditions has to be taken into account $[12,13]$.

2. A basic in vitro model of experimental SAH using blood, CSF, heme oxygenase- 1 , and rat arachnoid membranes was used to study the oxidation of unconjugated bilirubin by the cytochrome oxidase [14].

3. A computational analysis using a benchtop model consisting of a cranial vault attached to an idealized anatomical replica of the spinal canal allows the estimation of SAH clearance from cerebrospinal fluid (CSF) [15].

These-more or less advanced-cell cultures and basic in vitro models are promising tools that can lead to a more detailed understanding of the complex intracellular processes following SAH, e.g., to study changes in intracellular molecular pathways in response to $\mathrm{SAH}$, increased pressure, or hypoxia. However, the pathophysiology of $\mathrm{SAH}$ is an orchestra of anatomical, mechanical, physiological, and molecular mechanisms, including impairments of cerebral perfusion, neuronal signaling and cellular energy balance, neuroinflammatory responses, and disruption of CSF circulation [16]. Simple cell culture and basic in vitro models clearly cannot depict these mechanisms-hence, more refined models are needed. An example of this represents the in vitro $\mathrm{SAH}-$ model of the perfused retina. The retinae used as a part of the central nervous system are usually a waste product generated in 
abattoirs since they cannot be further processed into food. Therefore, such retinae may serve as good to study neurovascular coupling and impairment of neuronal signaling by subarachnoid blood [17, 18]. Moreover, this model allows studying the impact of single cellular molecules or pathways for the pathophysiology of SAH [19].

Next to these established in vitro SAH models, some recent developments might be of great interest and potential for further SAH in vitro studies:

1. The brain-on-a-chip model allows the cultivation of different human cells in microfluidic chips. Using modifiable microchannels and microdomains inside the chip, a multicellular microenvironment that is able to imitate the neurophysiological conditions in the human brain with great accuracy can be created [20-22]. In the past few years, the brain-on-a-chip method allowed to depict neurophysiological processes and mechanisms of the human brain as well as pathological conditions [23-28]. Therefore, brain-on-a-chip models might be powerful tools for drug screening and disease modeling applications. So far, the brain-on-a-chip technique has not been used to model SAH, but it might be a promising approach in SAH research.

2. Embryonic stem cells are pluripotent in nature and capable of unlimited differentiation of any cell type. The possibility to create induced pluripotent stem cells (iPSCs) using artificial reprogramming of human somatic cells poses a modern possibility of modeling various organs in a preclinical environment. One such example is brain organoids which are complex and self-organizing threedimensional (3D) systems that can be generated via differentiating iPSCs towards neuroectoderm lineages. These brain organoids are "brain-like neuroepithelial tissues" that constitute various cell types ranging from multipotent stem cells to layer-specific neurons whose cytoarchitecture is similar to its in vivo counterparts [29-32]. They show brain functionality and neurogenesis comparable to human neurophysiology [33, 34]. Generation of brain organoids with a vascular system is not possible since vasculature and endothelial cells originate from the mesoderm. Nevertheless, inducing a vascular system spontaneously within the brain organoids is essential for neurophysiological and neuroanatomic completion of organoid structures. Additionally, vascularization in brain organoids could enhance oxygen and nutrition supply, allowing culturing brain organoids for the long term. Recent efforts of co-culturing of endothelial cells and neurospheres resulted in the formation of vascularized brain organoids [35]. Further advancement was as induction of endothelial cells within brain organoids via an ectopic expression of ETS variant 2 (ETV2). This approach surprisingly generated functional vasculatures in brain organoids [36].

Taken together, brain organoids have the potential to fill the gap between in vitro cell cultures and in vivo animal models [37-40]. Indeed, Wang et al. [41] were able to use the self-organizing neural characteristic of brain organoids in a preclinical setting as part of the treatment of mice after SAH: comparing SAH-mice with and without organoid models, apoptosis was observed in less neurons when organoid models were implanted [41]. Furthermore, neurotransmitterrelated neurons were formed due to synaptic connections between brain organoids and the host brain.

So far, neither a brain-on-a-chip nor a brain organoid model has been established to study SAH and further studies have to clarify as to how far they are suitable to portray the human SAH pathophysiology and to develop new therapeutic approaches. In contrast to animal models, brain organoids have the advantage to offer personalized brain organoids when generated from iPSCs derived from individual patients. These organoids, as part of individualized medicine, may completely portray the individual patient with his genetic composition [42]. Therefore, these brain organoids will at least complement in vivo animal studies. Taken together with recently developed non-mammal animal models (e.g., zebrafish), this might substitute "classical" animal models in preclinical stroke research as discussed above [43, 44].

In conclusion, there exists a dilemma in translational SAH research: new therapeutic approaches are urgently needed but translation from bench to bedside with animal models has largely failed. Cell culture and basic in vitro models likely enable an analysis of some intracellular processes but are unable to give a complete picture. More advanced models are promising but have not yet been established except for the perfused retina model.

Consequently, future research has to focus on the refinement of sophisticated in vitro SAH models, such as a brain-on-a-chip or a brain organoid model. As in vitro approaches will unlikely replace animal experiments completely, differences in the pathophysiology of SAH between different species must be analyzed and standardization in experimental SAH has to be aimed for.

Funding Open Access funding enabled and organized by Projekt DEAL.

\section{Declarations}

Ethical Approval No studies involving human participants or animals were conducted for this article by any of the authors.

Conflict of Interest The authors declare no competing interests. 
Open Access This article is licensed under a Creative Commons Attribution 4.0 International License, which permits use, sharing, adaptation, distribution and reproduction in any medium or format, as long as you give appropriate credit to the original author(s) and the source, provide a link to the Creative Commons licence, and indicate if changes were made. The images or other third party material in this article are included in the article's Creative Commons licence, unless indicated otherwise in a credit line to the material. If material is not included in the article's Creative Commons licence and your intended use is not permitted by statutory regulation or exceeds the permitted use, you will need to obtain permission directly from the copyright holder. To view a copy of this licence, visit http://creativecommons.org/licenses/by/4.0/.

\section{References}

1. Feigin VL, Lawes CM, Bennett DA, Anderson CS. Stroke epidemiology: a review of population-based studies of incidence, prevalence, and case-fatality in the late 20th century. Lancet Neurol. 2003. https://doi.org/10.1016/s1474-4422(03)00266-7.

2. Nieuwkamp DJ, Setz LE, Algra A, Linn FH, de Rooij NK, Rinkel GJ. Changes in case fatality of aneurysmal subarachnoid haemorrhage over time, according to age, sex, and region: a meta-analysis. Lancet Neurol. 2009. https://doi.org/10.1016/S1474-4422(09) 70126-7.

3. Stegmayr B, Eriksson M, Asplund K. Declining mortality from subarachnoid hemorrhage: changes in incidence and case fatality from 1985 through 2000. Stroke. 2004. https://doi.org/10.1161/ 01.STR.0000138451.07853.b6.

4. Etminan N, Vergouwen MD, Ilodigwe D, Macdonald RL. Effect of pharmaceutical treatment on vasospasm, delayed cerebral ischemia, and clinical outcome in patients with aneurysmal subarachnoid hemorrhage: a systematic review and meta-analysis. J Cereb Blood Flow Metab. 2011. https://doi.org/10.1038/jcbfm. 2011.7.

5. Macdonald RL. Delayed neurological deterioration after subarachnoid hemorrhage. Nat Rev Neurol. 2014. https://doi.org/10.1038/ nrneurol.2013.246.

6. D’Abbondanza JA, Ai J, Lass E, Wan H, Brathwaite S, Tso MK, et al. Robust effects of genetic background on responses to subarachnoid hemorrhage in mice. J Cereb Blood Flow Metab. 2015. https://doi.org/10.1177/0271678X15612489.

7. D’Abbondanza JA, Lass E, Ai J, Loch MR. Mouse genetic background is associated with variation in secondary complications after subarachnoid hemorrhage. Acta Neurochir Suppl. 2015. https://doi.org/10.1007/978-3-319-04981-6_5.

8. Allen AL. The diagnosis of acetaminophen toxicosis in a cat. Can Vet J. 2003;44(6):509-10.

9. Van Lieshout JH, Marbacher S, Muhammad S, Boogaarts HD, Bartels HMA, et al. Proposed definition of experimental secondary ischemia for mouse subarachnoid hemorrhage. Transl Stroke Res. 2020. https://doi.org/10.1007/s12975-020-00796-y.

10. Kamp MA, Steiger HJ, van Lieshout JH. Experimental aneurysmal subarachnoid hemorrhage: tiding over. Trans Stroke Res. 2019. https://doi.org/10.1007/s12975-019-00726-7.

11. Kamp MA, Lieshout JH, Dibue-Adjei M, Weber JK, Schneider $\mathrm{T}$, Restin $\mathrm{T}$, et al. A systematic and meta-analysis of mortality in experimental mouse models analyzing delayed cerebral ischemia after subarachnoid hemorrhage. Transl Stroke Res. 2017. https:// doi.org/10.1007/s12975-016-0513-3.

12. Sun Q, Wu W, Hu YC, Li H, Zhang D, Li S, Wei L et al. Early release of high-mobility group box 1 (HMGB1) from neurons in experimental subarachnoid hemorrhage in vivo and in vitro. $\mathbf{J}$ Neuroinflammation. https://doi.org/10.1186/1742-2094-11-106.
13. Pluta RM, Jung CS, Harvey-White J, Whitehead A, Shilad S et al. In vitro and in vivo effects of probucol on hydrolysis of asymmetric dimethyl L-arginine and vasospasm in primates. J Neurosurg. 2005.

14. Loftspring MC, Wurster WL, Pyne-Geithman GJ, Clark JF. An in vitro model of aneurysmal subarachnoid hemorrhage: oxidation of unconjugated bilirubin by cytochrome oxidase. J Neurochem. 2007. https://doi.org/10.1111/j.1471-4159.2007.04667.x.

15. Tangen K, Narasimhan NS, Sierzega K, Preden T, Alaraj A, Linninger AA. Clearance of subarachnoid hemorrhage from the cerebrospinal fluid in computational and in vitro models. Ann Biomed Eng. 2016. https://doi.org/10.1007/s10439-016-1681-8.

16. Van Lieshout JH, Dibué-Adjei M, Cornelius JF, Slotty PJ, Schneider T, Restin T, Boogaarts HD, Steiger HJ, Petridis AK, Kamp MA. An introduction to the pathophysiology of aneurysmal subarachnoid hemorrhage. Neurosurg Rev. 2018;41(4):917-30. https:// doi.org/10.1007/s10143-017-0827-y.

17. Albanna W, Kotliar K, Lüke JN, Alpdogan S, Conzen C, Lindauer $\mathrm{U}$, et al. Non-invasive evaluation of neurovascular coupling in the murine retina by dynamic retinal vessel analysis. PLoS ONE. 2018. https://doi.org/10.1371/journal.pone.0204689.

18. Albanna W, Lüke JN, Schubert GA, Dibue-Adjei M, Kotliar K, Hescheler $\mathrm{J}$ et al. Modulation of Cav2.3 channels by unconjugated bilirubin (UCB) - candidate mechanism for UCB-induced neuromodulation and neurotoxicity. Mol Cell Neurosci. 2019. https:// doi.org/10.1016/j.men.2019.03.003.

19. Albanna W, Neumaier F, Lüke JN, Kotliar K, Conzen C, Lindauer U, Hescheler J, Clusmann H, Schneider T, Schubert GA. Unconjugated bilirubin modulates neuronal signaling only in wild-type mice, but not after ablation of the R-type/Ca 2.3 voltage-gated calcium channel. CNS Neurosci Ther. 2018;24(3):222-230. https://doi.org/10.1111/cns.12791. Epub 2017 Dec 23. PMID: 29274300; PMCID: PMC6489700.

20. Pamies D, Hartung T, Hogberg HT. Biological and medical applications of a brain-on-a-chip. Exp Biol Med. 2014. https://doi.org/ $10.1177 / 1535370214537738$.

21. Miccoli B, Braeken D, Li YCE (2019). Brain-on-a-chip devices for drug screening and disease modeling applications. Current Pharmaceutical Design. 2019. https://doi.org/10.2174/13816 12825666190220161254

22. Kilic O, Pamies D, Lavell E, Schiapparelli P, Feng Y, Hartung T, Bal-Price A, Hogberg HT, et al. Brain-on-a-chip model enables analysis of human neuronal differentiation and chemotaxis. Lab Chip. 2016. https://doi.org/10.1039/c6lc00946h.

23. Moreno EL, Hachi S, Hemmer K, Trietsch SJ, Baumuratov AS, Hankemeier T, Vulto Schwamborn JC, et al. Differentiation of neuroepithelial stem cells into functional dopaminergic neurons in 3D microfluidic cell culture. Lab Chip. 2015. https://doi.org/ 10.1007/s12035-019-01653-2.

24. Griep L, Wolbers F, De Wagenaar B, ter Braak PM, Weksler B, Romero IA, Couraud P, Vermes I, et al. BBB on chip: microfluidic platform to mechanically and biochemically modulate blood-brain barrier function. Biomed Microdevices. 2013. https://doi.org/10. 1007/s10544-012-9699-7.

25. Sandlin ZD, Shou M, Shackman JG, Kennedy RT. Microfluidic electrophoresis chip coupled to microdialysis for in vivo monitoring of amino acid neurotransmitters. Anal Chem. 2005. https://doi. org/10.1021/ac051044z.

26. Wang Y, Ma J, Li N, Wang L, Shen L, Sun Y, Wang Y, Zhao J et al. Microfluidic engineering of neural stem cell niches for fate determination. Biomicrofluidics. 2017.https://doi.org/10.1063/1. 4974902

27. Fan Y, Nguyen DT, Akay Y, Xu F, Akay M. Engineering a brain cancer chip for high-throughput drug screening. Sci Rep. 2016. https://doi.org/10.1038/srep25062. 
28. Achyuta AKH, Conway AJ, Crouse RB, Bannister EC, Lee RN, Katnik CP, Behensky AA, Cuevas J, et al. A modular approach to create a neurovascular unit-on-a-chip. Lab Chip. 2013. https:// doi.org/10.1039/c2lc41033h.

29. Lancaster MA, Renner M, Martin CA, Wenzel D, Bicknell LS, Hurles ME, Homfray T, Penninger JM, Jackson AP, Knoblich JA. Cerebral organoids model human brain development and microcephaly. Nature. 2013. https://doi.org/10.1038/nature12517.

30. Lancaster MA, Knoblich JA. Generation of cerebral organoids from human pluripotent stem cells. Nat Protoc. 2014. https://doi. org/10.1038/nprot.2014.158.

31. Gopalakrishnan J. The emergence of stem cell-based brain organoids: trends and challenges. BioEssays. 2019. https://doi.org/10. 1002/bies.201900011.

32. Pasca SP. The rise of three-dimensional human brain cultures. Nature. 2018. https://doi.org/10.1038/nature25032.

33. Paşca AM, Sloan SA, Clarke LE, Tian Y, Makinson CD, et al. Functional cortical neurons and astrocytes from human pluripotent stem cells in 3D culture. Nat Methods. 2015. https://doi.org/ 10.1038/nmeth.3415.

34. Quadrato G, Nguyen T, Macosko EZ, Sherwood JL, Yang SM, et al. Cell diversity and network dynamics in photosensitive human brain organoids. Nature. 2017. https://doi.org/10.1038/ nature22047.

35. Shi Y, Sun L, Wang M, Liu J, Zhong S, Li R, Li P, Guo L, Fang A, Chen R, Ge WP, Wu Q, Wang X. Vascularized human cortical organoids (vOrganoids) model cortical development in vivo. PLoS Biol. 2020;18(5): e3000705. https://doi.org/10.1371/journal.pbio. 3000705.

36. Cakir B, Xiang Y, Tanaka Y, Kural MH, Parent M, Kang YJ, Chapeton K, Patterson B, Yuan Y, He CS, Raredon MSB, Dengelegi J, Kim KY, Sun P, Zhong M, Lee S, Patra P, Hyder F, Niklason LE, Lee SH, Yoon YS, Park IH. Engineering of human brain organoids with a functional vascular-like system. Nat Methods. 2019 Nov;16(11):1169-1175. https://doi.org/10.1038/s41592019-0586-5. Epub 2019 Oct 7. PMID: 31591580; PMCID: PMC6918722.
37. Goranci-Buzhala G, Mariappan A, Gabriel E, Ramani A, Ricci-Vitiani L, Buccarelli M, D’Alessandris QG, Pallini R, Gopalakrishnan J. Rapid and efficient invasion assay of glioblastoma in human brain organoids. Cell Rep. 2020. https://doi.org/ 10.1016/j.celrep.2020.107738.

38. Gabriel E, Ramani A, Altinisik N, Gopalakrishnan J. Human brain organoids to decode mechanisms of microcephaly. Front Cell Neurosci. 2020. https://doi.org/10.3389/fncel.2020.00115.

39. Gabriel E, Ramani A, Karow U, Gottardo M, Natarajan K, Gooi LM, Goranci-Buzhala G, Krut O, Peters F, Nikolic M, et al. Recent zika virus isolates induce premature differentiation of neural progenitors in human brain organoids. Cell Stem Cell. 2017. https://doi.org/10.1016/j.stem.2016.12.005.

40. Ramani A, Müller L, Ostermann PN, Gabriel E, Abida-Islam P, Müller-Schiffmann A, Mariappan A, Goureau O, Gruell H et al. SARS-CoV-2 targets neurons of 3D human brain organoids. EMBO J. 2020. https://doi.org/10.15252/embj.2020106230.

41. Wang SN, Wang Z, Xu TY, Cheng MH, Li WL, Miao CY. Cerebral organoids repair ischemic stroke brain injury. Transl Stroke Res. 2019. https://doi.org/10.1007/s12975-019-00773-0.

42. Wen Z, Christian KM, Song H, Ming GL. Modeling psychiatric disorders with patient-derived iPSCs. Curr Opin Neurobiol. 2016. https://doi.org/10.1016/j.conb.2015.11.003.

43. Yu X, Li YV. Zebrafish (Danio rerio) Developed as an alternative animal model for focal ischemic stroke. Acta Neurochir Suppl. 2016;121:115-9. https://doi.org/10.1007/978-3-319-18497-5_20

44. Chen W, Xie L, Yu F, Li Y, Chen C, Xie W, Huang T, Zhang Y, Zhang S, Li P. Zebrafish as a model for in-depth mechanistic study for stroke. Transl Stroke Res. 2021 May 29. doi: https://doi.org/ 10.1007/s12975-021-00907-3. Epub ahead of print

Publisher's Note Springer Nature remains neutral with regard to jurisdictional claims in published maps and institutional affiliations. 